\title{
ECOLOGIA DE MICROALGAS E EDUCAÇÃO AMBIENTAL: AVALIANDO A PERCEPÇÃO AMBIENTAL E SENSIBILIZANDO PESCADORES DA LAGOA MÃE-BÁ (GUARAPARI-ANCHIETA, ES)
}

\author{
Juliana Miranda Ferreira ${ }^{1}$ \\ Lidiane Pereira da Silva² \\ Valéria de Oliveira Fernandes ${ }^{3}$ \\ Michell Pedruzzi Mendes Araújo ${ }^{4}$
}

Resumo: A presente pesquisa visou desenvolver atividades teóricas e práticas que permitissem a avaliação da percepção ambiental de pescadores participantes do Projeto Piscicultura da lagoa Mãe-Bá (Guarapari - Anchieta, ES) e introdução de conhecimentos acerca do funcionamento deste ecossistema aquático, enfocando a importância das algas como bioindicadoras da qualidade da água e a sua aplicação para o manejo sustentável. A partir da fala dos pescadores entrevistados e por meio das representações em mapas mentais, é possível inferir que o trabalho de Educação Ambiental, mesmo em curto prazo e de maneira pontual como realizado neste estudo, se mostrou bastante eficaz em termos de mudanças iniciais de percepção ambiental.

Palavras-chave: Microalgas; Percepção Ambiental; Lagoa Costeira; Ecologia; Educação Ambiental.

${ }^{1}$ Sedu-ES. E-mail: jumirferreira@gmail.com. Link para o Lattes: http://lattes.cnpq.br/0115854200474977.

${ }^{2}$ Sedu-ES. E-mail: lidypersi@hotmail.com. Link para o Lattes: http://lattes.cnpq.br/3790884848712403.

${ }^{3}$ Universidade Federal do Espírito Santo. E-mail: valeriaufes@yahoo.com.br.

Link para o Lattes: http://lattes.cnpq.br/2323760323729607.

${ }^{4}$ Universidade Federal de Goiás. E-mail: michellpedruzzi@ufg.br.

Link para o Lattes: http://lattes.cnpq.br/6141634183456644.

Revbea, São Paulo, v.16, № 1: 78-95, 2021. 
Abstract: This research aimed to develop theoretical and practical activities that would allow the assessment of the environmental perception of fishermen participating in the Pisciculture Project of the Mãe-Bá lagoon (Guarapari Anchieta, ES, Brazil) and the introduction of knowledge about the functioning of this aquatic ecosystem, focusing on the importance of algae as bioindicators water quality and its application for sustainable management. From the speech of the interviewed fishermen and through the representations in mental maps, it is possible to infer that the environmental education work, even in the short term and in a punctual manner as carried out in this study, proved to be quite effective in terms of initial changes in environmental perception.

Keywords: Microalgae; Environmental perception; Coastal Lagoon; Ecology; Environmental education.

\section{Introdução}

Dentre as regiões habitadas no planeta, a costeira é tida como uma das mais ocupadas por grandes centros urbanos. A importância dos ecossistemas costeiros parte do princípio de que o alimento, a possibilidade de construção de moradia, o lazer, o desenvolvimento tecnológico, a saúde e outros fatores advêm desses ambientes (GOMES, 2005).

As lagoas costeiras apresentam elevada biodiversidade, atuam como berçário e criadouros de diversas espécies de aves, peixes, crustáceos e anfíbios, servindo como fonte de renda para várias comunidades (ESTEVES; ROLAND; BOZELLI, 1990). São extremamente importantes econômica e socialmente, sendo utilizadas para pesca, artesanatos a partir de plantas aquáticas, turismo, irrigação, abastecimento e harmonia paisagística.

Devido ao potencial de utilização pela população, as margens das lagoas costeiras passaram a atrair construções imobiliárias de veraneio e turismo, já que a presença da lagoa valoriza a região com sua beleza e possibilidades de lazer. No entanto, esta ocupação desordenada, na maioria das vezes, descaracteriza a paisagem e acelera a deterioração das condições ecológicas desses ambientes (ESTEVES et al., 1990).

Uma das consequências desastrosas da ação do homem nas lagoas costeiras é a eutrofização, aumento considerável de nutrientes na água (ESTEVES, 2011), principalmente em decorrência do lançamento de efluentes domésticos, industriais e agrícolas e disposição inadequada de resíduos sólidos (lixo orgânico).

Como o aumento da eutrofização ocorre de maneira drástica e acentuada, há inúmeras implicações negativas na ecologia destes ecossistemas, como por exemplo, o aumento da incidência de explosões reprodutivas de microalgas (florações ou blooms), especialmente de cianobactérias. Tal fato acarreta queda na qualidade da água, por modificar suas características organolépticas (cor, sabor, odor) e por serem 
potencialmente tóxicas, podendo ser letais a diversos animais da cadeia trófica, inclusive ao homem, com a possibilidade de tornar o ecossistema inutilizável para quaisquer finalidades. Além disso, o ecossistema apresenta queda na biodiversidade aquática e apenas espécies tolerantes à poluição passam a sobreviver, havendo quebra da estabilidade do sistema.

Neste contexto, para que haja compreensão da interação entre o homem e o meio ambiente é necessário que a sua percepção, que vem sempre acompanhada da atribuição de valores e tomada de posições seja analisada tanto do ponto de vista cognitivo (conhecimento), como do afetivo (MACHADO, 1999). Ainda de acordo com esse autor, os problemas humanos mais importantes emergem de fenômenos que não podem ser estudados por um enfoque científico tradicional, já que resultam de uma atividade perceptiva das pessoas em relação às condições ambientais criadas por e para elas.

Os processos de percepção ambiental são atividades mentais de interação do indivíduo com o ambiente. Seu estudo é de fundamental importância para que se possam compreender melhor as inter-relações entre o homem e o ambiente, suas expectativas, satisfações e insatisfações, julgamentos e condutas (BECHARA, 2007). Desta maneira, podem-se utilizar os estudos sobre a percepção ambiental como ferramenta para que se atinjam os valores, interesses e o conhecimento sobre o meio ambiente particular de cada público-alvo, assim como descobrir como estes indivíduos percebem e descrevem o meio ambiente (BARROS; MIGUEL, 2007).

Segundo Lopes (2004), o grande desafio do nosso tempo é criar as comunidades sustentáveis, ou seja, ambientes sociais e culturais nos quais possamos satisfazer nossas necessidades sem diminuir as chances das gerações futuras. De acordo com Tristão (2004), para alcançar práticas mais sustentáveis, é necessário examinar com mais rigor o impacto que a globalização provoca. Um princípio básico se torna ameaçado: a diversidade biológica e social da vida contemporânea, com sua influência homogeneizadora da cultura, da padronização, do anonimato e a potente substituição da comunicação pela simples informação.

Os princípios da Educação Ambiental para sociedades sustentáveis têm pensamento crítico, questionador e transformador da sociedade como elemento fundamental para a formação de cidadãos com consciência local e planetária. Para se atingir esse objetivo associado ao sucesso esperado, devem-se vencer as seguintes etapas: despertar o interesse das pessoas no problema ambiental que se quer trabalhar, promover a mobilização social, trocar conhecimento, planejar ações e monitorar e avaliar resultados.

Os benefícios trazidos pela ciência são inegáveis, porém existe uma série de conhecimentos que não estão nos livros e alguns cientistas desconhecem. Por este motivo, o respeito a diferentes formas do saber pode ser o início para o fortalecimento do trabalho em conjunto entre pesquisadores e os demais representantes da sociedade (LOPES, 2004). Afinal, o papel da ciência deve ser 0 de oferecer alternativas a problemas existentes e os 
cientistas precisam ter consciência da importância da sua atuação junto à sociedade, na forma de diálogo, ações e decisões pensadas em conjunto, para que dessa forma haja reflexão sobre os impactos sociais e culturais das ações realizadas.

Segundo Jarvis (2013), nossa aprendizagem é influenciada pelo contexto social em que ela ocorre. É, portanto, a combinação de processos pelos quais a pessoa inteira, corpo e mente, experiencia as situações sociais, ao longo de sua vida. O conteúdo recebido é transformado no sentido cognitivo, emotivo ou prático e integrado à sua biografia individual, que resulta em um sujeito em constante processo de mudança. Esta se torna perceptível na próxima situação social em que o indivíduo entrar e favorecer novas/outras transformações. Nesse caminho, as emoções são transformadas, as opiniões são afetadas, assim como muitas atitudes e valores.

Assim sendo, o estudo da percepção dos sujeitos ativos sobre o ecossistema em questão e a realização de atividades de Educação Ambiental, mesmo que pontuais e em curto prazo, foram realizados com o intuito de verificar e considerar a significância do valor histórico cultural, responsável pela manutenção da identidade de cada público e a importância da ciência difundida na sociedade. Segundo Lopes (2004), apenas repassar conhecimento à população também não é suficiente, é preciso incluí-la na tomada de decisões.

Diante do exposto, a presente pesquisa visou desenvolver atividades teóricas e práticas que permitissem a avaliação da percepção ambiental de pescadores participantes do Projeto Piscicultura da lagoa Mãe-Bá (Guarapari Anchieta, ES) e introdução de conhecimentos acerca do funcionamento deste ecossistema aquático, enfocando a importância das algas como bioindicadoras da qualidade da água e a sua aplicação para o manejo sustentável. Objetivouse então, facilitar o entendimento e permitir que todos compreendessem e participassem das etapas de uma pesquisa científica, incentivando assim a atuação da população como agente modificador deste meio e buscando a melhoria da qualidade de vida, já que a lagoa Mãe-Bá apresenta elevada importância regional pela multiplicidade de usos e por apresentar indícios de eutrofização artificial nos últimos anos.

\section{A lagoa Mãe-Bá}

A lagoa Mãe-Bá, também conhecida como Maimbá, é a segunda maior lagoa em termos de extensão do Espírito Santo e está localizada entre os municípios de Guarapari e Anchieta.

Por ser um ecossistema cercado por aglomerados urbanos e comunidades rurais, a lagoa Mãe-Bá é muito utilizada para pesca, abastecimento, higiene (lavagem de roupas, utensílios), lazer, recreação e irrigação de culturas. 
A bacia hidrográfica da lagoa Mãe-Bá vem sendo ocupada de maneira desordenada, apresentando desmatamento nas nascentes e nas margens dos córregos e lagoas. A lagoa Mãe-Bá e seus córregos tributários vêm sendo submetidos a diversas formas de impacto antrópico, tais como assoreamento, descarga inadequada de efluentes domésticos e industriais, além de resíduos sólidos de diversas origens, os quais têm acarretado no aumento crescente de nutrientes e, consequentemente, da eutrofização, com registros de florações de microalgas e queda da qualidade da água, tornando-se imprópria para múltiplos usos.

Algumas pesquisas foram realizadas pelo LATEAC (Laboratório de Taxonomia e Ecologia de Algas Continentais) da UFES para compreender a dinâmica da lagoa Mãe-Bá e identificar as suas possíveis alterações ecológicas, sempre utilizando microalgas como bioindicadores da qualidade ambiental. Estas pesquisas contaram com o apoio logístico da Samarco Mineradora, localizada às margens deste ecossistema.

Um grupo de dez pescadores de comunidades do entorno da lagoa participou do Projeto Piscicultura, um projeto piloto de colocação de tanquesrede na lagoa para criação de tilápia em parceria com a Samarco Mineração $\mathrm{S} / \mathrm{A}$ e desconheciam a qualidade da água, o que seriam as microalgas e sua relação com a cor esverdeada da lagoa.

Então, surgiu a ideia, novamente com o apoio da empresa, de desenvolver um estudo de percepção ambiental deste grupo de pescadores, utilizando as microalgas como principal objeto de estudo.

\section{Conhecendo as microalgas}

Foram realizados quatro encontros no Centro de Convivência e Educação Ambiental (CCEAM) da Samarco Mineradora (Anchieta, ES). Em cada um foram realizadas palestras, atividades práticas de coleta de microalgas na lagoa Mãe-Bá, reconhecimento dos organismos e discussão das percepções obtidas, além da aplicação de questionários (Anexos 1 e 2) e mapas mentais, desenhos feitos pelos sujeitos, interpretados como uma representação pessoal e organizada do meio físico que os cerca.

Os objetivos dessas atividades foram reiterar a necessidade de manutenção de equilíbrio na lagoa e dos organismos que ali vivem, evidenciando os impactos antrópicos aos quais está submetida e quanto às medidas mitigadoras dos mesmos. Foi visada a sensibilização, além de estreitar a relação entre comunidade científica e pescadores residentes na área de entorno da lagoa, demonstrando os resultados das pesquisas ecológicas que vem sendo desenvolvidas. Ao final das atividades com o grupo, comparamos os resultados obtidos antes e após o desenvolvimento das mesmas, para avaliar se houve sensibilização dos sujeitos quanto à importância da conservação dos ecossistemas aquáticos. 
Primeiramente houve a apresentação do trabalho, aplicação dos questionários de avaliação prévia das concepções dos pescadores e mapas mentais, a fim de explorar as representações associadas à lagoa Mãe-Bá. Nesse percurso, os sujeitos tiveram que representar a comunidade de seres vivos que vivem dentro e no entorno do ecossistema em questão. Esta atividade foi realizada antes de qualquer palestra ou explicação mais detalhada sobre o assunto, de forma proposital para melhor avaliação dos resultados.

Após a primeira etapa das atividades, realizou-se a primeira palestra com a utilização de slides informativos e explicativos enfocando em linguagem de fácil acesso, conteúdos como a importância da água e dos ecossistemas costeiros, conceito de eutrofização, informações relevantes sobre a lagoa MãeBá, suas formas de utilização, principais impactos, organismos encontrados na lagoa e seus respectivos papéis na cadeia alimentar. Em outro momento, foi ministrada palestra com o objetivo principal de apresentar a comunidade de microalgas, sua importância para os ecossistemas aquáticos, como são coletadas e identificadas, problemas relacionados aos processos de eutrofização e discussão sobre as possíveis soluções para a problemática.

Outra atividade realizada foi o trabalho de campo na lagoa para coleta de microalgas na região onde estava sendo desenvolvido o Projeto Piscicultura, demonstrando como essa atividade de pesquisa é feita (Figura 1). Em seguida, as amostras foram levadas ao laboratório do Centro de Convivência e Educação Ambiental da Samarco (CCEAM) onde foram montadas lâminas, as quais foram analisadas ao microscópio óptico para a identificação dos organismos coletados, objetivando a visualização das microalgas e seus tipos pelos pescadores. Destaca-se que alguns dos pescadores participaram ativamente das etapas da simulação de um trabalho de campo e que todos observaram as microalgas em laboratório.

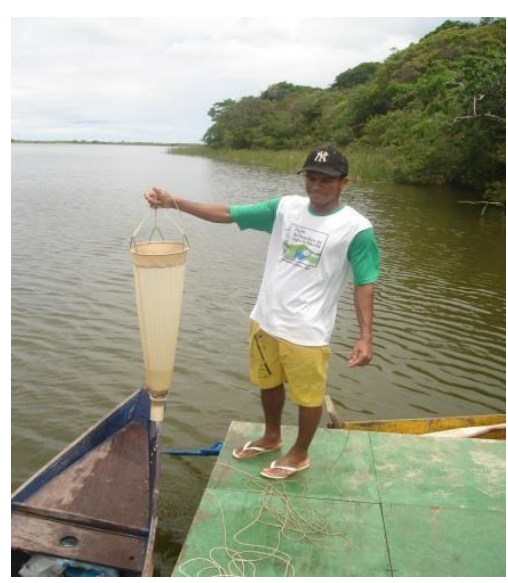

A

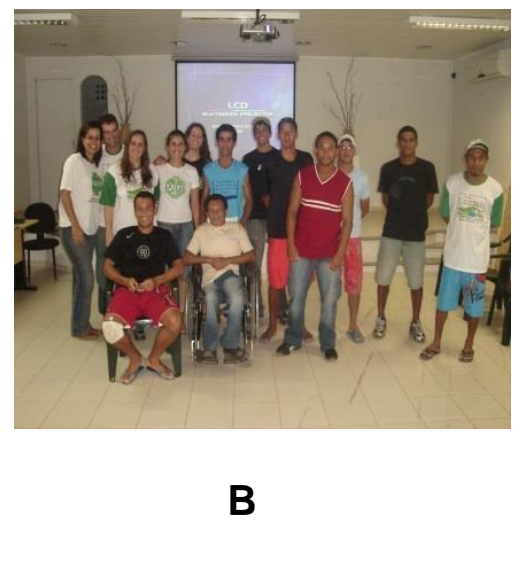

Figura 1: (A) Atividades de coleta de fitoplâncton e perifíton na lagoa Mãe-Bá, próximo aos tanques redes. (B) Equipe participante da pesquisa. (C) Observação dos organismos coletados ao microscópio.

Fonte: Acervo dos pesquisadores.

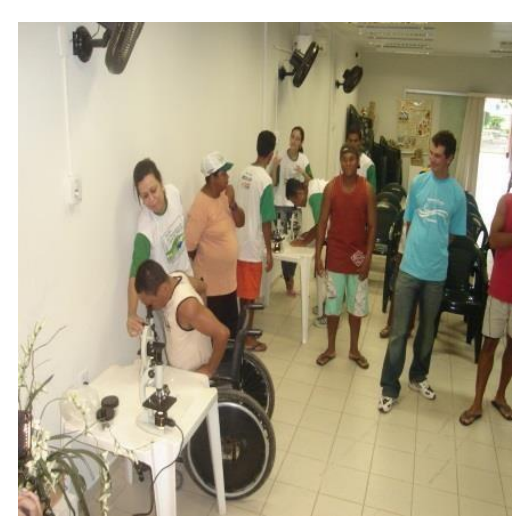

C 
Por último, foi aplicado outro questionário de avaliação para os pescadores e novamente o mapa mental com o mesmo objetivo de representação dos organismos encontrados na lagoa Mãe-Bá e seu entorno, a fim de avaliar as mudanças de percepção obtidas antes e após todas as atividades. Foi também realizada uma discussão final sobre tudo o que foi abordado nos encontros e sobre o papel de cada um na mudança de atitudes visando à preservação da lagoa.

\section{Avaliando a percepção ambiental dos pescadores}

Os resultados das perguntas realizadas antes das atividades, apenas a partir do conhecimento prévio e de vivências dos pescadores, mostraram que a lagoa Mãe-Bá é vista por todos os sujeitos principalmente como fonte de renda e benefícios às comunidades de seu entorno em diversos aspectos, como a pesca, o artesanato, o turismo, o lazer, entre outros.

Alguns discursos mostram também uma percepção inicial dos sujeitos acerca das profundas alterações que esse ambiente vem sofrendo em suas condições naturais: "Hoje está um pouco ruim devido à poluição"...; "Acredito que vamos beber água direto do poço", evidenciando que o ambiente poderia ser melhor aproveitado se não existissem esses fatores de poluição, que são causados principalmente por uma relação desarmônica com o ecossistema, por meio do lançamento de efluentes domésticos, industriais, agrícolas, além da disposição inadequada de resíduos sólidos (lixo).

Quatro ideias centrais foram retiradas das falas dos sujeitos que demonstraram a importância da lagoa como instrumento essencial à vida da população que dela se utiliza diretamente para diversos fins, além de alguns demonstrarem certa preocupação com as mudanças negativas observadas na lagoa Mãe-Bá, muito provavelmente devido aos prejuízos econômicos refletidos por esses impactos na população nos últimos anos. Dessas ideias foram montados discursos, a partir de trechos de cada resposta, conhecido como Discurso do Sujeito Coletivo (DSC), segundo Lefèvre e Lefèvre (2003).

O DSC constitui uma técnica de pesquisa qualitativa, em que é descrito como um discurso-síntese, elaborado com pedaços de falas de sentido semelhante reunidos em um só texto, para fazer uma coletividade "falar", como se fossem um só indivíduo. É uma técnica de tabulação e organização de dados qualitativos que resolve um dos grandes impasses desse tipo de pesquisa, na medida em que permite, por meio de procedimentos sistemáticos e padronizados, agregar depoimentos sem reduzi-los em quantidade.

Os DSC's que demonstraram as ideias centrais discutidas acima são:

revista brasileira

educação

ambiental
"Mãe-Bá é conhecida por causa da lagoa, a maravilha que ela é. Possui uma vista maravilhosa que atrai vários turistas. Proporciona benefícios aos pescadores com a pesca, tem que estar limpa, sem lixo, como fonte de renda, artesanato com a 
taboa que atrai pessoas de outras cidades, alimentos, 0 turismo, o paisagismo. Barriga cheia! O projeto TABOA LAGOA e o Núcleo de Piscicultura que trouxe oportunidades para todos os pescadores da região." - Ideia Central A

"Hoje está um pouco ruim devido à poluição, mas antes era muito bom o pescado e a água limpa." - Ideia Central B

"Acredito que vamos beber água direto do poço, degustar vários peixes, além de nos oferecer um contato maior com a natureza." - Ideia Central C

"Proporciona prática de esportes e lazer" - Ideia Central D

Outro resultado significativo, demonstrado por meio do discurso retirado da única ideia central, quando perguntado quanto às mudanças que ocorreram na lagoa Mãe-Bá nos últimos anos devido ao processo de eutrofização que a lagoa vem sofrendo, revelou que a maioria dos sujeitos nota mudanças negativas ocorridas na lagoa no decorrer do tempo, principalmente relacionados à mudança de coloração, ao crescimento da taboa, aumento da quantidade de algas e diminuição de peixes, o que evidencia uma percepção inicial dos sujeitos em relação às consequências causadas pela interferência humana no ecossistema, reunidas no DSC abaixo:

"Sim, a lagoa não é a mesma de antes, tem muito mais taboa, lama, algas e os peixes estão sumindo. A lagoa ficou mais poluída, antes podíamos observar vários animais, hoje em dia é difícil, os peixes foram se acabando pouco a pouco. A cor era muito clara, agora está muito escura, com muito organismo orgânico. A lagoa está mais suja, amarela e com muita taboa".

Alguns dos entrevistados não sabiam relatar os sinais de eutrofização artificial, porém entendiam de certa forma citando-os nas respostas como sendo "efeitos de poluição", o aumento das taboas e algas e diminuição dos peixes.

Esse discurso demonstra também que esse processo de eutrofização artificial a que a lagoa Mãe-Bá está submetida nos últimos anos não é apenas observado, mas também motivo de preocupação e insatisfação da população, já que traz prejuízos, ("[...] os peixes estão sumindo [...]"; "os peixes foram se acabando pouco a pouco...") e desconforto ambiental ("A lagoa está mais suja, amarela e com muita taboa").

A percepção negativa em relação às mudanças ocorridas na lagoa nos últimos anos se manteve depois das atividades de Educação Ambiental realizadas. O resultado era esperado, já que durante as palestras e atividades de coleta e identificação dos organismos presentes na lagoa, principalmente das microalgas indicadoras da qualidade do ambiente, foram bastante

revista brasileira educação ambiental 
ressaltadas e discutidas as evidências que comprovam o crescente processo de eutrofização que a lagoa Mãe-Bá vem sofrendo nos últimos anos, tendo como consequência a diminuição da quantidade e qualidade de várias populações de organismos, principalmente peixes e o aumento da vegetação (plantas aquáticas).

A mudança de coloração foi mais uma vez apontada como uma alteração na qualidade da água da lagoa, porém, notou-se que desta vez vinculada ao aumento da concentração de microalgas.

"Sim. A cada ano que passa a água fica mais escura e aparecem vários tipos de sujeira na superfície, o aparecimento de algas e o aumento de lixo na água, o crescimento de turistas com lanchas e o aparecimento de muitas algas na margem. A água está mais turva, têm menos peixes, cada vez mais lama e mais vegetação, principalmente taboa. Antes não tinha taboa e a água era limpa e agora está suja, a quantidade de peixe diminuiu e a qualidade da água era clara, está ficando mais escura, cheia de algas ruins, que não são boas para a lagoa".

Pode-se deduzir, a partir do discurso montado, que a presença de alguns tipos de microalgas e as consequências de sua presença e número no ambiente foram compreendidas pelos sujeitos, como mostram as expressões presentes no discurso: "algas ruins"; "algas que não são boas para a lagoa", vinculadas principalmente à presença de cianobactérias, algas potencialmente tóxicas, que foram bastante discutidas e mostradas por meio dos trabalhos já realizados na lagoa nos últimos anos. Tais discussões emergiram durante a visualização das amostras coletadas pelos próprios pescadores em uma das atividades realizadas, muitas vezes identificadas por eles mesmos durante a exibição de fotos durante as palestras.

Os dois discursos gerados a partir de duas ideias centrais mostraram que os sujeitos têm consciência de que a maioria dos efluentes domésticos gerados pelas suas comunidades entra em contato direto ou indireto com a lagoa Mãe-Bá.

"Na maioria das casas o esgoto são as fossas, como nossa comunidade não tem rede de esgoto, cada um constrói seu tratamento de esgoto, o que acaba afetando o nosso solo" Ideia central $\mathrm{A}$;

"Ainda encontramos pessoas que não sabem o que faz e jogam o esgoto de pia na lagoa. Algumas casas moram bem perto da lagoa, com certeza alguns são desviados do seu recurso indo direto para a lagoa" - Ideia central B. 
Isso é motivo de grande preocupação já que se torna uma das principais causas da eutrofização artificial, como já discutido anteriormente, originando os principais impactos citados pelos próprios sujeitos no discurso referente à pergunta anterior.

Uma das perguntas realizadas no questionário inicial e repetida no final teve o objetivo de perceber a consciência dos sujeitos em relação às consequências trazidas pela sua própria interferência na lagoa e desenvolver, a partir daí, um pensamento crítico para promover mudanças de atitudes, e analisar o que as atividades de Educação Ambiental influenciaram na alteração de percepção dos sujeitos quanto a mudanças de atitudes e valores para a preservação da lagoa.

O conceito da aprendizagem transformativa está intrinsecamente ligado ao campo da educação de adultos. Para Mezirow (1996, p. 162), a aprendizagem é concebida "como o processo de utilizar as interpretações anteriores, com vista a construir uma interpretação nova, ou uma interpretação alterada acerca do sentido da experiência pessoal em ordem a guiar a ação futura". Tal pensamento foi influenciado, entre outras, pela perspectiva do construtivismo, principalmente pelas ideias de Freire de reflexão crítica e desenvolvimento intelectual/reflexivo. Portanto, a maior influência sobre a aprendizagem transformativa prende-se com a importância da reflexão. A reflexão está intimamente ligada à análise da experiência individual, pois é a partir dela que o indivíduo identifica o sentido e interpretações comuns do contexto social que o envolve, permitindo a tomada de estratégias com vista à transformação do comportamento individual e coletivo.

Os resultados obtidos a partir dos discursos gerados no questionário inicial apontaram como principais papéis do cidadão na conservação da lagoa: evitar a poluição (“...cada um fazer o seu papel, jogando lixo no lixo, não poluindo e se conscientizar". - Ideia Central B) e repassar os conhecimentos adquiridos para outras pessoas, como mostra a ideia central A ("Alertar as pessoas do que não se pode fazer, orientar para não jogarem lixo e esgoto nas margens e na lagoa...").

Os sujeitos demonstraram com as respostas que além de uma atitude ecológica comprometida, é importante transmitir os conhecimentos à sociedade, contribuindo assim para a maior tomada de consciência possível, evitando a degradação das lagoas costeiras.

Esta percepção se torna muito interessante, sob o ponto de vista da relevância de se repassar os conhecimentos ecológicos de preservação, já que, apesar da complexidade, a linguagem é potencialmente transformadora, podendo modificar o modo de pensar, de agir e de se relacionar com o meio ambiente (TRISTÃO, 2004).

É claro que os discursos montados a partir das falas dos sujeitos, apesar de poderem ser considerados como demonstrações de consciência a respeito de certas atitudes básicas mais sustentáveis em relação à 
conservação da lagoa, não afirmam que esta consciência seja efetivamente relevante no cotidiano dos cidadãos em questão.

Muitas vezes, as atividades de Educação Ambiental (EA) ensinam o que fazer e como fazer certo, transmitindo uma série de procedimentos ambientalmente corretos. Mas isso nem sempre garante a formação de uma atitude ecológica, isto é, de um sistema de valores sobre como relacionar-se com o meio ambiente, sistema que será internalizado com uma visão de mundo orientadora dos posicionamentos do sujeito na escola e em outros espaços e circunstâncias de sua vida (CARVALHO, 2004). De acordo com Jarvis (2013), temos que praticar aquilo que aprendemos ou repeti-los sistematicamente para depositá-los em nossa memória.

A discussão gerada pela ideia central A se mostra interessante para enfatizar um dos objetivos da Educação Ambiental em relação à importância da ciência não somente difundida pela comunidade científica, mas também por meio da sociedade de um modo geral. Sagan (1996) considera a divulgação científica como importante processo de despertar para que os cidadãos compreendam como o mundo funciona. E não somente isso, possibilitar a essas pessoas o fim da alienação e da não participação na construção do seu próprio futuro (SATO, 2002).

As respostas obtidas na avaliação final também apontaram 0 conhecimento do papel da educação, como forma de promover essa consciência dentro de si, como demonstra o discurso da ideia central A ("É aprender a ter consciência de preservação, dos problemas da lagoa. Cada um deve ter consciência de que lagoa, mar, rios devem ser mantidos limpos. Ter respeito com a lagoa e consciência ambiental').

A teoria da aprendizagem transformativa apresenta uma explicação acerca da transformação das perspectivas de sentido. Para Mezirow (1991), o processo de reflexão crítica é crucial para a justificação e validação de pressupostos. Refere-se ao processo de avaliar criticamente o conteúdo, o processo, ou as premissas dos nossos empenhos de interpretar e significar a experiência.

Outro ponto importante a ser destacado é que em nenhuma das falas dos sujeitos foram identificadas citações a respeito do papel do poder público na conservação dos recursos naturais. Tal aspecto demonstra falta de conhecimento dos deveres do setor público, não os enxergando como responsáveis pelas comunidades por meio da promoção de políticas públicas e exigência de seu cumprimento. Vale destacar que esse é um fator primordial para a manutenção e recuperação do meio ambiente, ademais, para garantia da educação de qualidade, da divulgação ou popularização da ciência e da alfabetização científica em uma perspectiva ambiental.

Outro resultado interessante é que dois discursos montados a partir das respostas significativas dos sujeitos mostraram que a maioria dos pescadores notou a presença de microalgas ou alguma característica que eles considerem similar na lagoa. Levando em consideração que a maior parte dos

Revbea, São Paulo, v.16, № 1: 78-95, 2021. 
sujeitos não tinha conhecimento a respeito destes seres e de como eles podem surgir no ambiente, pode-se afirmar por meio da interpretação dos discursos que é claramente observada a presença de alterações nas características naturais da lagoa.

"Sim, várias algas, em alguns cantos da lagoa, um 'lixo verde' no fundo."

"Não muito, de pequenas proporções".

O conhecimento dos sujeitos em relação aos tipos de microalgas existentes na lagoa após as atividades de Educação Ambiental teve o intuito de reforçar a importância e compreensão a respeito destes seres como bioindicadores da qualidade da água, visando maior entendimento sobre o assunto e aumentando a percepção dos sujeitos diretamente ligados a lagoa Mãe-Bá a respeito das mudanças na qualidade da água utilizada para diversos fins.

Os dois discursos demonstram a total assimilação em relação ao conceito de fitoplâncton e perifíton como os dois tipos de microalgas presentes em ambientes aquáticos e muito estudados para avaliar a qualidade destes ecossistemas, resultado este obtido por meio das abordagens durante todas as palestras, discussões e atividades práticas realizadas.

$\mathrm{Na}$ ideia central A, verificou-se maior assimilação dos sujeitos em relação às diferenças entre os dois tipos de microalgas abordados nas palestras e atividades.

"Fitoplâncton são as microalgas livres que ficam soltas e se movimentam na água, ficam no fundo e às vezes sobem para buscar claridade. Perifíton são algas que ficam grudadas, que se agarram nas gaiolas, galhos, taboa, em lixo, barcos, em alguma coisa, como o limo." - Ideia Central A

"Algas, 'bichinhos', limo" - Ideia Central B

Outro resultado importante foi a compreensão das consequências trazidas pelo grande aumento da concentração de microalgas devido ao processo de eutrofização artificial crescente na lagoa Mãe-Bá, após o trabalho de EA realizado.

O discurso exemplifica de maneira geral a conclusão tomada a respeito do entendimento das consequências trazidas pelo aumento da concentração destes organismos pelos sujeitos, já discutidas anteriormente. 
"Acaba deixando a água imprópria para a sobrevivência das espécies, porque podem consumir todo oxigênio da água, porque elas também respiram oxigênio e assim tira a respiração dos peixes ou produzirem toxinas e matarem os peixes ou outros animais. Seria prejudicial para 0 desenvolvimento dos peixes, porque a água fica poluída e a maioria morreria".

Pode-se concluir então, a partir dos resultados obtidos, que as atividades de Educação Ambiental realizadas com os pescadores foram de fundamental importância no aumento da compreensão destes sobre as verdadeiras razões que levam as consequências de certa forma já percebidas por eles no ambiente em que estão inseridos. Mister faz-se ressaltar que os resultados muitas vezes evidenciam a não percepção dos sujeitos sobre a participação deles como agentes modificadores do ambiente.

\section{Representando o mundo ao redor por meio de mapas mentais}

\section{Antes e após as atividades}

A análise dos mapas mentais foi feita identificando dados significativos, tais como a presença e ausência de certos organismos aquáticos percebidos pelos pescadores como parte do ecossistema, entre outras representações como a presença de lixo, efluentes ou outra característica que simbolizasse consequências da eutrofização no ambiente.

A aplicação dos mapas mentais teve como objetivo comparar a percepção ambiental pelos sujeitos (pescadores) a partir dos conhecimentos prévios adquiridos por meio das vivências e relação com a lagoa ao longo do tempo e após as atividades de Educação Ambiental (encontros realizados pelo estudo em questão), avaliando os novos conhecimentos adquiridos. Esse tipo de atividade, segundo Lopes (2004) representa a condição interativa entre o ser humano e o espaço. Estes autores ainda definem representações como particulares a cada indivíduo, porém ditas sociais por conter valores e julgamentos tomados da experiência em grupo. Os mapas são referidos como sendo processos por meio dos quais pode-se apropriar e compreender o mundo ao redor e como uma representação pessoal e organizada do meio físico.

Ao examinar os mapas mentais dos pescadores antes das atividades de EA e prática em campo na Lagoa Mãe-Bá, observou-se resultado similar aos encontrados nas perguntas do questionário de avaliação prévia dos pescadores que se referiram aos seres vivos observados na lagoa e seu entorno.

Na maioria dos mapas foram identificados principalmente peixes, aves aquáticas e outros animais já citados pelos discursos montados a partir do questionário, como cobras, lontra, camarão, além de vegetação, principalmente a taboa, muito presente em todo o entorno da lagoa (Figuras 2A à 2D). 
Notou-se também a presença do homem em alguns dos desenhos e sua relação com a lagoa, destacando a representação de barcos e pescadores, demonstrando a percepção dos sujeitos sobre a interferência e relações humanas com o ecossistema (Figuras 2A a 2D).
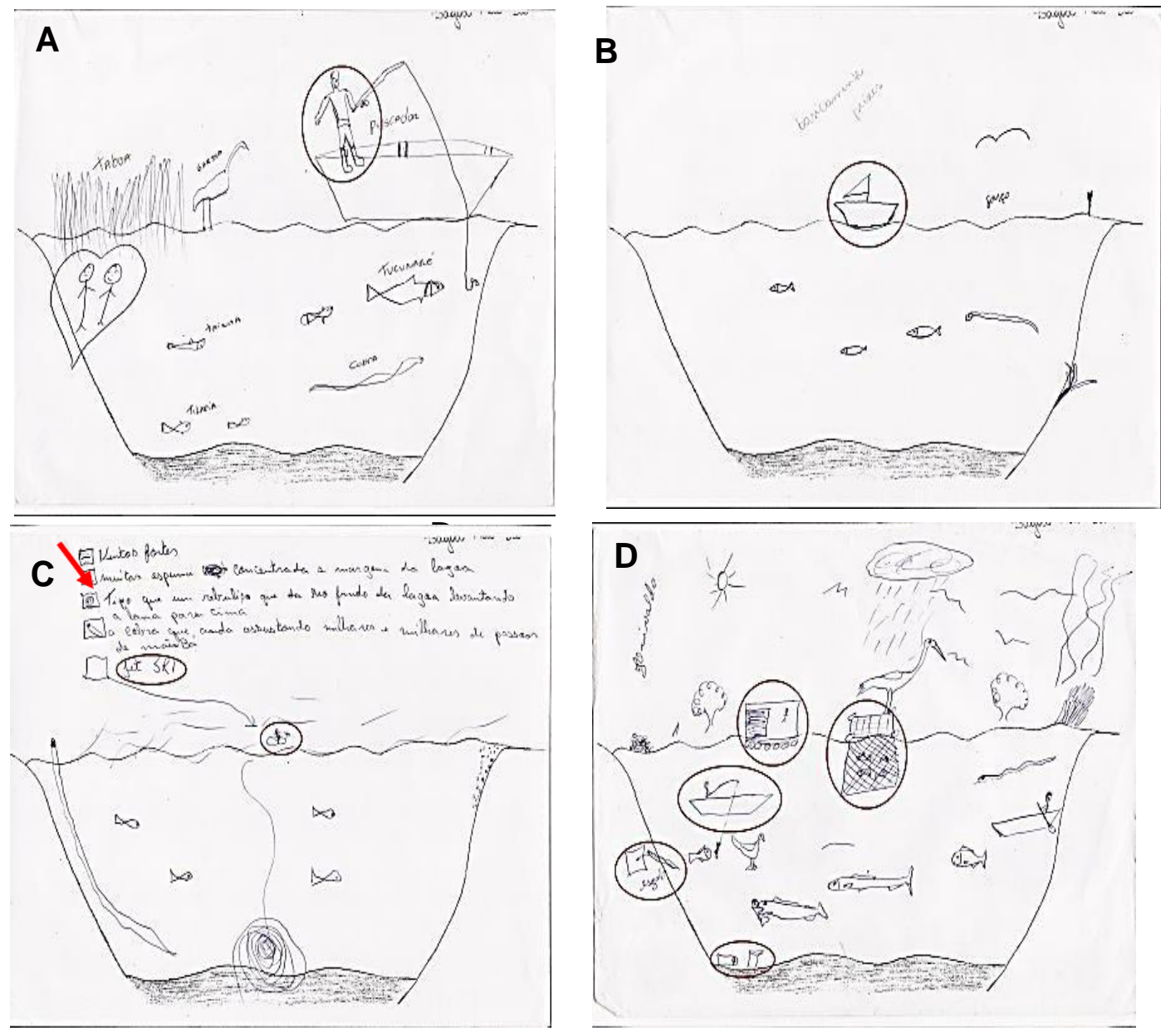

Figura 2: Mapas mentais construídos pelos pescadores antes das atividades de Educação Ambiental realizadas.

Fonte: Acervo dos pesquisadores.

Destacou-se também a presença de lixo, esgoto e outras características, como "espuma concentrada a margem da lagoa", apontado em um dos mapas mentais construídos (Figura 2C e 2D), podendo sugerir a presença de altas concentrações de um tipo de microalga, mesmo sem que o sujeito entenda e conheça essa relação, o que mais uma vez evidencia certa percepção inicial dos sujeitos sobre os sinais dos processos de eutrofização na lagoa.

Nos mapas mentais construídos após as atividades, algumas diferenças desvelam a assimilação dos novos conhecimentos adquiridos, como também ocorreu nos resultados dos questionários de avaliação final dos pescadores.

Revbea, São Paulo, v.16, № 1: 78-95, 2021. 
De acordo com Arruda (2002), o processo que dá sentido ao objeto que se apresenta a nossa compreensão é chamado de ancoragem. Trata-se da maneira pelo qual o conhecimento se enraíza no social e a volta dele convertese em categoria e integrar-se à grade de leitura do mundo do sujeito por meio da imagem, instrumentalizando o novo objeto.

Essa ancoragem é percebida por meio das novas representações do ambiente que os cerca, sendo agora encontrados além dos animais e plantas já percebidos inicialmente, elementos como "limo", citado no discurso para designar perifíton como algas aderidas a algum substrato, algas, destacandose o aparecimento de diversas formas de representações destas, livres na coluna d'água, presas a macrófitas, além da sua participação na cadeia alimentar (Figuras 3A, 3B e 3C) e a relação entre a quantidade de algas e a qualidade do ambiente (Figuras $3 \mathrm{D}$ e $3 \mathrm{E}$ ), entre outras demonstrações dos novos conhecimentos assimilados pelos sujeitos.
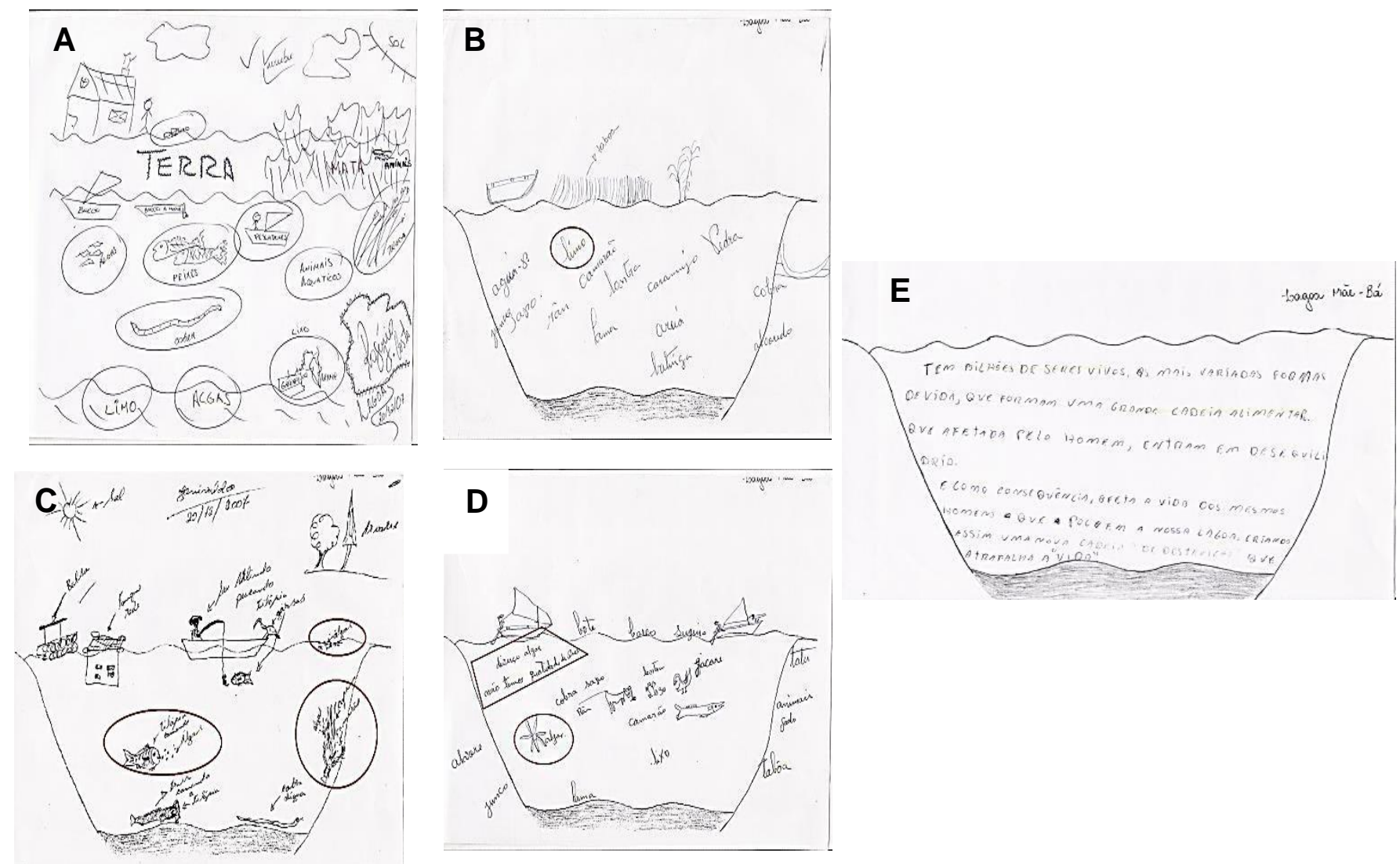

Figura 3: Mapas mentais construídos pelos pescadores após as atividades de Educação Ambiental realizadas.

Fonte: Acervo dos pesquisadores.

revista brasileira de

educação

ambiental
A presença de lixo e outras formas de poluição da lagoa ainda apareceram nos mapas e notou-se claramente o aumento na riqueza de seres vivos e mudança do olhar sob a lagoa Mãe-Bá.

Revbea, São Paulo, v.16, № 1: 78-95, 2021. 
Arruda (2002) ainda infere que o sujeito procede recorrendo ao que é familiar para fazer uma espécie de conversão da novidade: trazê-la ao território conhecido da nossa bagagem, ancorar aí o novo, o desconhecido, retirando-o da sua navegação às cegas pelas águas do não familiar.

\section{Considerações finais}

A realização de pesquisas que avaliem a percepção ambiental e verifiquem resultados após atividades de Educação Ambiental se mostra de suma relevância para o entendimento das relações socioculturais do indivíduo com os ecossistemas nos quais estão inseridos e de onde retiram recursos para seu sustento e sobrevivência. Além disso, por meio dessas atividades aumenta-se a compreensão sobre a necessidade emergente de se inserir a população como agentes transformadores do ambiente, de forma positiva, e despertam-se interesses e desvelam-se questões imprescindíveis: mudanças sociais, transformação de valores e sensibilização para a questão ambiental.

Pôde-se concluir, a partir das falas dos sujeitos entrevistados e por meio das representações em mapas mentais, que o trabalho de Educação Ambiental, mesmo em curto prazo e de maneira pontual como realizado neste estudo, se mostrou bastante eficaz em termos de mudanças iniciais de percepção ambiental.

Diante disso, cabe ainda a proposta da utilização das diversas formas de educação, formal ou informal, as discussões e inserções dos seres humanos no meio ambiente, buscando sensibilizar acerca da importância do uso racional dos recursos ambientais e das consequências trazidas pela interferência antrópica. Este processo supõe que os pesquisadores adotem uma linguagem apropriada, reafirmando os objetivos com situações abertas de diálogo com os interessados.

Espera-se, com os resultados da pesquisa, que a importância do entendimento das relações homem-natureza e mais profundamente os resultados obtidos por meio de pequenas ações de Educação Ambiental despertem a sensibilização da sociedade, científica ou não, incluindo a mídia e a escola a respeito de sua função e relevância na construção de valores sustentáveis, e consequentemente, na identificação de atitudes insustentáveis e suas consequências, bem como a capacidade de avaliar alternativas, ou seja, na construção de comunidades sustentáveis e consequente melhoria da qualidade de vida.

\section{Referências}

ARRUDA, A. Teoria das representações sociais e teoria de gênero. Cadernos de Pesquisa, n. 117, p. 127- 147. UFRJ. Rio de Janeiro, 2002.

BARROS, L. A. V.; MIGUEL, R. M. Estudo da Percepção Ambiental dos Funcionários da Limpeza do CEFETES. Vitória. CEFETES. 2007. (Trabalho de Conclusão de Curso-TCC). 
BECHARA, M. B. A Percepção Ambiental dos funcionários responsáveis pela limpeza do CCHN/UFES sobre a geração dos resíduos sólidos: Um breve diagnóstico. Vitória. UFES. 2007. (Monografia).

CARVALHO, I. C. M. Educação Ambiental: A formação do sujeito ecológico. São Paulo: Cortez, 2004.

ESTEVES, F. A.; ROLAND, F. \& BOZELLI, R. L. Lagoas costeiras do Rio de Janeiro: até quando? Ciência Hoje, v. 12, n. 68, p. 68-69. 1990.

ESTEVES, F. A. Fundamentos da limnologia. Rio de Janeiro: Interciência, 2011.

GOMES, E. C. Educação Ambiental em ecossistemas costeiros da Grande Vitória para alunos do ensino médio: Uma proposta multimídia. UFES, Vitória. 2005 (Monografia).

JARVIS, P. Aprendendo a ser uma pessoa na sociedade. Aprendendo a ser eu. In: ILLERIS, K. (Org.). Teorias contemporâneas da aprendizagem. Porto Alegre: Penso, 2013.

LEFÈVRE, F.; LEFÈVRE, A. M. C. O Discurso do Sujeito Coletivo: um novo enfoque em pesquisa qualitativa. Desdobramentos. Caxias do Sul, RS: EDUCS, 2003.

LOPES, A. F. A mediação de conceitos ecológicos e a consolidação de uma proposta de trabalho entre Escola e Universidade. UFRJ, Rio de Janeiro. 2004 (Dissertação).

MACHADO, L. M. C. P. A percepção do meio ambiente como suporte para Educação Ambiental. Departamento de Geografia, Instituto de Geociências e Ciências exatas - UNESP, Campus de Rio Claro, SP: União. p. 59-75. 1999.

MEZIROW, J. Transformative dimensions of adult learning. San Francisco, CA: Jossey-Bass, 1991.

MEZIROW, J. Contemporary paradigms of learning. Adult Education Quarterly, n. 46, v. 3, p. 158-172. 1996.

SAGAN, C. O mundo assombrado pelos demônios: a ciência vista como uma vela no escuro. São Paulo: Companhia das Letras, 1996.

SATO, M. Educação Ambiental. 2 ed. São Carlos: Rima, 2002.

TRISTÃO, M. A. Educação Ambiental na formação de professores: Rede de saberes. São Paulo: ANNABLUME, 2004.

revista brasileira 


\section{ANEXO 1}

\section{QUESTIONÁRIO DE ENTREVISTA PARA AVALIAÇÃO PRÉVIA DOS PESCADORES}

1- Quais os benefícios que a lagoa proporciona à sua comunidade?

2- Você observou alguma mudança na lagoa nos últimos tempos? Quais?

3- Você sabe para onde vai o esgoto doméstico da sua comunidade?

4- Quais os principais problemas que você acha que afetam a lagoa?

5- Qual o papel de cada cidadão para a conservação da lagoa?

6- Você saberia citar os tipos de seres vivos encontrados na lagoa?

7- Você já observou algum tipo de alga próximo, ou na, lagoa?

8- O que você acha que acontece aos organismos quando há interferência do homem na lagoa?

\section{ANEXO 2}

\section{QUESTIONÁRIO DE ENTREVISTA PARA AVALIAÇÃO FINAL DOS PESCADORES}

1- Você observou alguma mudança na lagoa nos últimos tempos? Quais?

2- Quais os principais problemas que você acha que afetam a lagoa?

3- Qual o papel de cada cidadão para a conservação da lagoa?

4- Você saberia citar os tipos de seres vivos encontrados na lagoa?

5- O que você entende por Fitoplâncton e Perifíton?

6- $\quad$ Em sua opinião, qual é a importância e quais são os benefícios das microalgas para o ambiente?

7- O que você acha que acontece aos organismos quando há interferência antrópica na lagoa?

8- Quais seriam os malefícios causados pelo rápido crescimento da comunidade de microalgas em um curto espaço de tempo? 